\title{
Cold Acclimation of Young Kiwifruit Vines under Artificial Hardening Conditions
}

\author{
Shaoli Lu and Mark Rieger \\ Department of Horticulture, University of Georgia, Athens GA 30602
}

Additional index words. Actinidia deliciosa, Actinidia chinensis, freezing stress, frost, cold hardiness, electrolyte leakage

\begin{abstract}
One-year-old kiwifruit [Actinidia deliciosa (A. Chev.) C.F. Liang et R. Ferguson var. deliciosa] vines were grown under 8- and 16-hour photoperiods to study the influence of photoperiod on cold acclimation and determine the potential level of hardiness that young vines attain. Vines were acclimated by reducing growth chamber temperature at 2-week intervals, beginning at 31/20C (16 hours/8 hours) and ending with $15 / 5 \mathrm{C}$ after 8 weeks. Vines receiving an 8 -hour photoperiod were more cold hardy than vines receiving a 16-hour photoperiod after 4 weeks of acclimation as determined by electrolyte leakage from stem tissues. Moreover, vines receiving an 8-hour photoperiod survived freezing at $-9 \mathrm{C}$ at the end of the 8-week acclimation period, whereas those receiving a 16-hour photoperiod were killed at - $6 \mathrm{C}$. Vine survival and electrolyte leakage of sterns were highly correlated $(r=-0.79$ to -0.90$)$.
\end{abstract}

Kiwifruit is a potential high cash-value crop that can be grown in warm, temperate regions of the world where the length of the growing season is $\approx 220$ days (Ferguson, 1990). Numerous small plantings exist in the southeastern United States, but the high cost of planting establishment and freeze injury have precluded expansion of current acreage. Spring frost damage to growing shoots can be avoided by various means of frost protection, but freeze damage to young vines during late autumn or winter is difficult to prevent.

Young vines ( $\leq 3$ years) are often killed to the ground by freezes in late autumn despite temperatures of these events being greater than or equal to - 3C (Bullard, 1987; Krewer et al., 1988). However, such vines can withstand about $-10 \mathrm{C}$ in midwinter if they are not killed in late autumn (Hewett and Young, 1981; Testolin and Messina, 1987). This difference suggests that cold acclimation does occur in kiwifruit vines but proceeds too slowly or begins too late in autumn to prevent freeze injury in the southeastern United States. Severe freeze injury has been observed by us on young 'Hayward', 'Matua', and 'Tomouri' vines despite

Received for publication 28 Feb. 1990. A contribution of the Univ. of Georgia Agr. Expt. Sta., College Station, Athens. This research was supported by state and Hatch Act funds allocated to the Georgia Agr. Expt. Stas. The cost of publishing this paper was defrayed in part by the payment of page charges. Under postal regulations, this paper therefore must be hereby marked advertisement solely to indicate this fact. exposure to relatively low temperatures and short photoperiods that induce cold hardiness in most woody deciduous plants (Fuchigami et al., 1971; Harrison et al., 1978; Pyke et al., 1986; van Huystee et al., 1967). This study was performed to determine the influence of photoperiod on cold acclimation of young kiwifruit vines, and to determine the potential level of cold hardiness that may develop in young vines under artificial hardening conditions.

Plant material. The male cultivar Tomouri was used in this study since it is the principal pollinizer for 'Hayward' (female) and had similar winter survival to 'Hayward' in previous years (unpublished data). Semihardwood cuttings were rooted in 2 perlite : 1 peat $(\mathrm{v} / \mathrm{v})$ medium under intermittent mist in Mar. 1988. Stem bases were wounded and treated with the potassium salt of indole-3butyric acid at $5 \mathrm{~g}$-liter ${ }^{-1}$. Cuttings were transplanted to 15 -cm-diameter (2.6 liter) pots, grown outdoors for one season, and overwintered in a protected location. Growth resumed in Mar. 1989, and 40 uniform vines were transferred to a growth chamber for cold acclimation experiments on 22 May 1989. Vines were allowed to acclimate to growth chamber conditions (31C day/25C night, 16$\mathrm{hr}$ photoperiod) for 24 days before cold acclimation.

Cold acclimation. All 40 vines were exposed to a temperature regime similar to that reported to increase cold hardiness in both temperate arid subtropical woody plants (Fuchigami et al., 1971; Yelenosky, 1976). Temperature was reduced over 8 weeks as follows: $31 / 20 \mathrm{C}(16 \mathrm{hr} / 8 \mathrm{hr})$ for weeks 1 and 


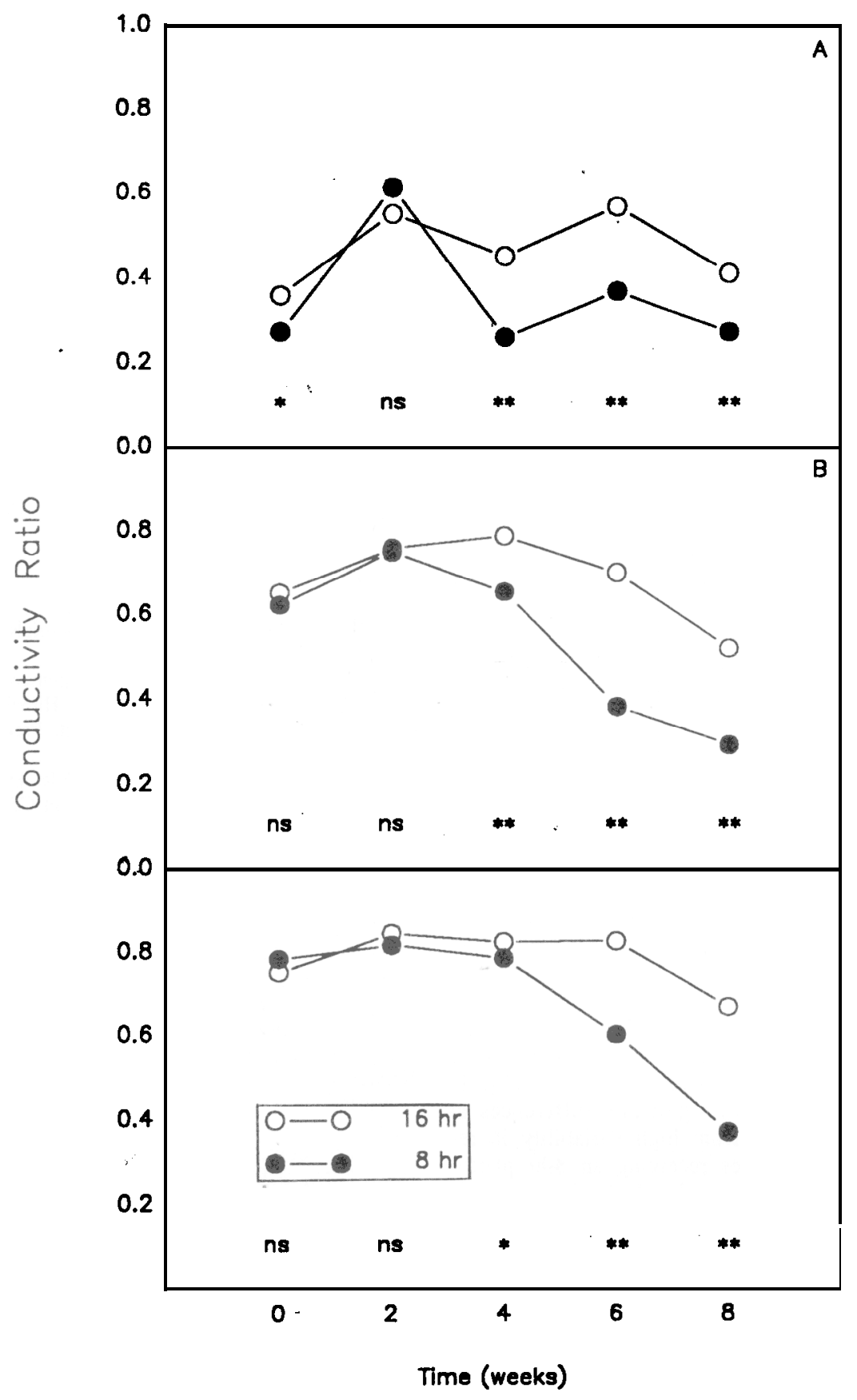

Fig. 1. conductivity ratio of 1-cm stem samples taken from 1-year-old 'Tomouri' kiwifruit vines during an 8-week cold acclimation period and frozen at -2 (A), -4 (B), or $-6 \mathrm{C}$ (C). Each symbol represents the mean of 10 samples. Significance oft test between photoperiod treatments within date is indicated along the abscissa; ns, *,** denote nonsignificance or significance at $P=0.05$ or 0.01 , respectively.

2, 25/15C for weeks 3 and 4, 16/10C for weeks 5 and 6 , and $15 / 5 \mathrm{C}$ for weeks 7 and 8 . The growth chamber was programmed to give a photoperiod of $16 \mathrm{hr}$, and an $8-\mathrm{hr}$ photoperiod was imposed on half of the vines by covering them with cardboard boxes halfway through, the programmed photoperiod. The boxes were ventilated from below so that temperature remained within $\pm 0.5 \mathrm{C}$ between treatments. Therefore, vines receiving an 8-hr photoperiod experienced high temperatures for the first half of the dark period, followed by low temperatures for the second $8 \mathrm{hr}$. Vines were watered as necessary to avoid soil water deficit. Relative humidity in. the chamber was uncontrolled, and ranged from $\gg 50 \%$ to $98 \%$. Light was provided by incandescent and fluorescent lamps that gave an average irradiance of $570 \mu \mathrm{mol} \cdot \mathrm{s}^{-1} \cdot \mathrm{m}^{-2}$ at the top of the plant canopy.

Electrolyte leakage. Stem sections $(1 \mathrm{~cm}$ long) were collected from the vines initially and at the end of each 2 -week period for determination of apparent cold hardiness by means of electrolyte leakage. Thirty stem sections were collected at random among the 20 plants in each photoperiod treatment, and 10 stem sections were frozen at $-2,-4$,

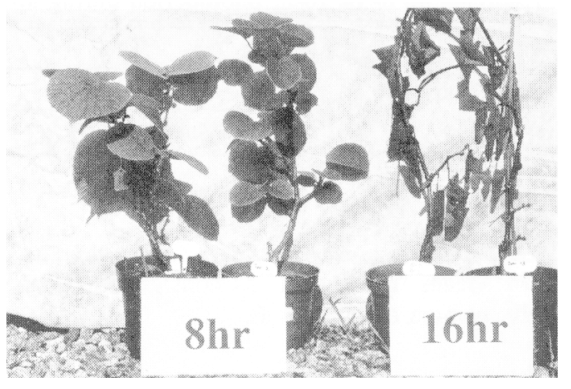

Fig. 2. Regrowth of 1-year-old 'Tomouri' kiwifruit vines 31 days after freezing at $-6 \mathrm{C}$. Vines exposed to an 8-hr photoperiod (left) or a 16-hr photoperiod (right).

and $-6 \mathrm{C}$ in a temperature-controlled bath. A small amount of crushed ice was placed in contact with the samples to prevent supercooling. Temperature was decreased at 1 to $2 \mathrm{C} / \mathrm{hr}$ and maintained at minima for $1 \mathrm{hr}$. Samples were removed and thawed slowly in an ice/water mixture for $1 \mathrm{hr}$, then transferred into test tubes containing $15 \mathrm{ml}$ deionized water and maintained at $\approx 25 \mathrm{C}$ for 24 $\mathrm{hr}$ to allow electrolytes to be leached from tissues. Conductivity of the solution (mmhos) was measured with a YSI model 31 conductivity bridge (Yellow Springs Instrument, Yellow Springs, Ohio). Stem sections were then killed by holding them at $70 \mathrm{C}$ for 15 rein; they then were left for $24 \mathrm{hr}$ at room temperature before the second measurement of conductivity. The ratio of solution conductivity after freezing to that after heat killing was then calculated, and is hereafter referred to as the conductivity ratio. Preliminary studies with nonacclimated 'Hayward', 'Matua', and 'Tomouri' showed that conductivity ratios $>0.54$ were associated with death (oxidative browning of tissue) of stems, and ratios $<0.42$ indicated that stems survived freezing.

Whole-vine freezing. Freezing tests on whole vines were conducted at the end of the 8 -week cold acclimation period. Six vines from each photoperiod treatment were frozen in a programmable freezer at $-3,-6$, and $-9 \mathrm{C}( \pm 0.2 \mathrm{C})$ for $3 \mathrm{hr}$, with a temperature change rate of $1 \mathrm{C} / \mathrm{hr}$.Leaves and stems were misted with water to prevent supercooling. Pots were wrapped with fiberglass insulation to prevent freezing of roots. Temperatures of the air, soil, and stems were monitored with 24-gauge (0.5-mm diameter) t-type thermocouples and a CR21x data logger (Campbell Scientific, Logan, Utah). Thermocouples were inserted into the bark to monitor stem temperature. Vines were removed from the freezer after temperatures had returned to $\approx 4 \mathrm{C}$, and stem sections were taken from each vine for measurement of conductivity ratio as described. Vines were taken to a greenhouse for assessment of freezing injury and regrowth over 6 weeks. Stem dieback was expressed as length of dead stem: total stem length, and new growth was measured to the nearest centimeter.

Data were analyzed by t test between photoperiod treatments at each sampling date and 
Table 1. Stem dieback and regrowth 31 days after freezing of 1-year-old 'Tomouri' kiwifruit vines receiving an 8- or 16-hr photoperiod during artificial hardening conditions.

\begin{tabular}{|c|c|c|c|c|c|c|}
\hline \multirow{3}{*}{$\begin{array}{l}\text { Photoperiod } \\
\text { (hr) }\end{array}$} & \multicolumn{6}{|c|}{ Freezing temperature $\left({ }^{\circ} \mathrm{C}\right)$} \\
\hline & -3 & -6 & -9 & -3 & -6 & -9 \\
\hline & \multicolumn{3}{|c|}{ Stem dieback $(\%)$} & \multicolumn{3}{|c|}{ Regrowth $(\mathrm{cm})$} \\
\hline 16 & 35 & 100 & 100 & 11.7 & 0.0 & 0.0 \\
\hline 8 & 0 & 0 & 14 & 10.7 & 9.8 & 9.7 \\
\hline Significance & & & & N S & & NS \\
\hline
\end{tabular}

$\widehat{N S, *, * *}$ Means within columns nonsignificant, or significantly different at $P=0.05$ or 0.01 , respectively, using a $t$ test, $\mathrm{n}=6$.

freezing temperature. A correlation was performed on conductivity ratio for semihardwood and hardwood stem samples vs. survival to determine the suitability of the conductivity data for assessing cold hardiness.

Whole-vine freeze survival and conductivity ratio of stem tissues were negatively correlated $(r=-0.79$ and -0.90 for hardwood and semihardwood samples, respectively). Generally, if the conductivity ratio was $>0.6$, the vine from which the sample was taken was completely killed. If the ratio was $<0.2$, no stem injury was observed; when it was 0.2 to 0.6 , partial stem dieback was observed. These results are similar to those obtained on nonacclimated vines in preliminary studies. Therefore, the electrolyte leakage method provided a gross index of cold acclimation status of kiwifruit vines and may provide a simple method for assessing cold hardiness of young vines in the "field.

Photoperiod significantly influenced conductivity ratio during acclimation (Fig. 1). At week 0 , no differences existed in conductivity ratio at -4 or $-6 \mathrm{C}$, although at $-2 \mathrm{C}$ the conductivity ratio was slightly higher for vines selected for the 8-hr than the 16-hr photoperiod. Reasons for this initial difference at only $-2 \mathrm{C}$ are unclear and probably unimportant because after 2 weeks at 31/20C, the conductivity ratio was similar for vines in either treatment at all test temperatures. Differences in the conductivity ratio between vines due to photoperiod occurred at all freezing temperatures after week 4 (Fig. 1). Thus, photoperiod began to influence apparent cold hardiness of stems between weeks 2 and 4, when the vines were at 25/15C. It cannot be determined from this experiment whether this change occurred in response to an interaction between photoperiod and temperature or photoperiod alone. Differences in conductivity ratio between photoperiod treatments increased at subsequent sampling dates, and by week 8 , conductivity ratio for vines in the 8 -hr photoperiod treatment was below the 0.6 threshold at all temperatures, whereas it was above 0.6 at $-6 \mathrm{C}$ for vines receiving the $16-\mathrm{hr}$ photoperiod.

Vines receiving a 16-hr photoperiod were entirely killed when frozen at -6 and $-9 \mathrm{C}$, whereas all vines receiving an 8 -hr photoperiod survived freezing at these temperatures (Table 1). Observations of freezing injury revealed that hardwood stems showed greater dieback than semihardwood, regardless of photoperiod treatment. In some cases, only the distal 1 to $3 \mathrm{~cm}$ of semihardwood stems was injured while hardwood stems on the same plant often were killed entirely. This result is consistent with observations of the lower $0.5 \mathrm{~m}$ of the trunk (hardwood) of young vines dying while younger stems are uninjured after the first freeze in autumn (Bullard, 1987; Krewer et al., 1988). Thus, the progression of cold acclimation in kiwifruit vines may be basipetal, indicating that freeze protection efforts should focus specifically on trunk protection (Krewer et al., 1988).

Regrowth 31 days after freezing was greater for vines receiving the 8 -hr than the 16-hr photoperiod when frozen at $-6 \mathrm{C}$ (Table 1 , Fig. 2). Lack of significant differences at $-9 \mathrm{C}$ resulted from high variability in regrowth for vines receiving an 8-hr photoperiod, despite complete lack of regrowth of vines receiving a 16-hr photoperiod. Regrowth of vines frozen at $-3 \mathrm{C}$ was also variable and occurred largely from axillary buds not subtended by leaves.

A short photoperiod during gradual exposure to low, nonfreezing temperatures enhanced cold acclimation of young kiwifruit the same environmental cues as other temperate woody plants (Fuchigami et al., 1971). Under these conditions, young vines acclimated to freezing temperatures well below vines, indicating that kiwifruit responds to those expected in the southeastern United States during late autumn, although it remains unclear why this does not occur in the field. Bullard (1987) attributed the lack of cold hardening to fluctuating temperatures that are typical of autumn and winter in the southeastern United States. However, diurnal temperature fluctuation of $\approx 10 \mathrm{C}$ occurred during most of the acclimation period, suggesting that intermittent warming on a daily basis does not impede cold acclimation. The effect of long periods of intermittent moderate temperatures (days or weeks) on cold acclimation of kiwifruit vines should be investigated in further studies. Results reported here with l-year-old vines agree with those reported previously showing that mature kiwifruit vines can acclimate to withstand temperatures of about $-10 \mathrm{C}$ or lower without injury (Hewett and Young, 1981; Testolin and Messina, 1987).

\section{Literature Cited}

Bullard, A.J. 1987. Actinidia chinensis-trials and tribulations. Pomona 10(3):68-69.

Ferguson, A.R. 1990. Kiwifruit management, p. 472-503. In: G.R. Galletta and D.G. Himelrick (eds.). Small fruit crop management. Prentice Hall, Englewood Cliffs, N.J.

Fuchigami, L.H., C.J. Weiser, and D.R. Evert. 1971. Induction of cold acclimation in Cornus slolonifera Michx. Plant Physiol. 47:98-103.

Harrison, L.C., C.J. Weiser, and M.J. Burke. 1978. Environmental and seasonal factors affecting the frost-induced stage of cold acclimation in Cornus stolonifera Michx. Plant Physiol. 62:894-898.

Hewett, E.W. and K. Young. 1981. Critical freezing damage temperatures of flower buds of kiwifruit (Actinidia chinensis Planch.). N.Z. J. Agr. Res. 24:73-75.

Krewer, G., P. Sumner, and T. Hall. 1988. Trunk protection for reducing cold injury of kiwifruit. vol. 3. Proc. Southeastern Professional Fruit Workers Conf. Paper no. 13.

Pyke, N.B., C.J. Stanley, and I.J. Barrington. 1986. Kiwifruit: frost tolerance of plants in controlled conditions. N.Z. J. Expt. Agr. 14:443447.

Testolin, R. and R. Messina. 1987. Winter cold tolerance of kiwifruit. A survey after frost injury' in Northern Italy. N.Z. J. Expt. Agr. 15:504-510.

van Huystee, R.B., C.J. Weiser, and P.H. Li. 1967. Cold acclimation in Cornus stolonifera under natural and controlled photoperiod and temperature. Bot. Gaz. 128:200-205.

Yelenosky, G. 1976. Ice tolerance of cold-hardened 'Valencia' orange wood. Cryobiology $13: 243-247$. 